\title{
A Response to Acerbi on Netz, Noel, Tchernetska, and Wilson edd. The Archimedes Palimpsest ${ }^{\star}$
}

Reviel Netz

Stanford University revielnetz@gmail.com

In a notice concerning The Archimedes Palimpsest ${ }^{1}$ published in Aestimatio 10 (2013) 34-46, Fabio Acerbi-attentive and erudite as ever-makes many comments, some of which I sympathize with. (Especially, when he notes the aukuardness of the choice to mark dialect variations-a choice that ended up over-burdening the apparatus; Heiberg's opposite choice put us in a bind). Putting aside several minor remarks, I respond to the two main substantive claims.

1. That the diagram set of Spiral Lines 13 in Codex A included not just an impossible figure but also another, normalized one

This claim, which has potential ramifications for the nature of the ancient diagram, is based on the evidence of copies BDEG. In fact, the normalized diagram in $\mathrm{E}$ is in a second hand, while those of BDG are each differently oriented. We are left with the evidence of $\mathrm{EH} 4$, each (in its original state) with just a radically impossible figure, as against BDG, each with just a normalized diagram-and each distinct. Note that:

(i) no copy contained the putative dual set of diagrams (both impossible and normalized),

(ii) this is in fact typical. In general, EH4 tend to copy automatically what we may reconstruct as the source in A while BG (and sometimes D) introduce variations based on their oun mathematical understanding (so, for instance, with the arcs of the polygon in Sphere and

* See http://www.ircps.org/aestimatio/10/34-46.

1 R. Netz, W. Noel, N. Tchernetska, and N. Wilson edd. Cambridge: Cambridge University Press, 2011. 2 vols. Pp. 700. ISBN 978-1-107-01684-2. Cloth £150, \$240.00.

(C) 2013 Institute for Research in Classical Philosophy and Science All rights reserved
ISSN 1549-4497 (online) ISSN 1549-4470 (print) 
Cylinder1, generally preserved by EH4 but sometimes 'corrected', in various ways, by $B G$ and, occasionally, $D$. It would be a very thin reed indeed, to suggest that the arcs of the polygon could have been independently introduced by EH4).

The reconstruction of Codex A with only the radically impossible figure-identical to that of $\mathrm{C}-$ is, therefore, virtually certain.

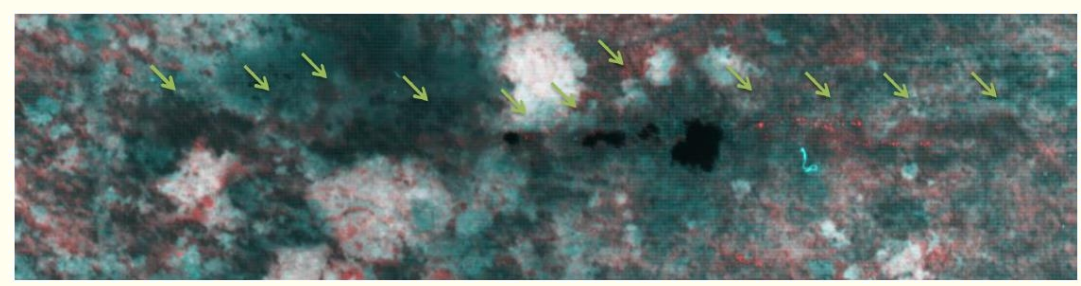

Figure 1

\section{That the reading of $\langle\pi \lambda \hat{\eta} \theta$ oc» in $177 \mathrm{v}$ col. 1.1 is baseless}

I attach here a pseudo-color image [Figure 1] of the first 11 letters of the line, arrous pointing at the letters (curiously, the fifth letter is now best read in the original Heiberg image, for which the reader is referred to the dataset). The reading is as difficult as it gets in this Archimedes manuscript but it is not in serious doubt. Of course, the reading of such a text does require a more intensive familiarity with the particular document because a great deal of the work involves eliminating alternative letter forms: one needs to know the precise details of the particular script as well as the pattern of damage to such letter forms. In my experience with students, it takes several months to acquire such skills.

I applaud Acerbi for his insistence that textual publications should serve as the beginning, not end, of critical revision (I have after all contributed to a revision of no less than Heiberg). However, when critical attitude turns into unbounded skepticism, one loses precisely the advantages of the editors' tacit knowledge-of their familiarity with the idiosyncrasies of a document. Far better would be to make one's best effort to follow in the editors' footsteps, while being willing to diverge from them.

That Acerbi did not make such an effort may be related to an undercurrent-which one would be disingenuous to ignore-of personal animus. I am 
reluctant to join this conversation and do so only because silence, under such circumstances, might be misconstrued. To prevent the future possibility of such misconstruals, it is best to make clear that this is my first, and last, response. 